\title{
Clinicopathological and prognostic significance of nestin expression in patients with breast cancer: a systematic review and meta-analysis
}

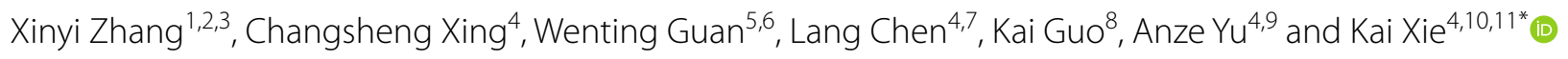

\begin{abstract}
Background: Nestin has been revealed to promote tumorigenesis, progression, metastasis, and angiogenesis of breast cancer. Although the prognostic and clinicopathological impact of nestin expression on breast cancer patients has been assessed in several independent studies, their results remained conflicting. Therefore, we performed this meta-analysis to elucidate the prognostic and clinicopathological association of nestin expression with breast cancer.

Methods: A comprehensive literature search was performed in the electronic databases PubMed, EMBASE, Web of Science, the Cochrane Library, China National Knowledge Infrastructure (CNKI), and the Wangfang Data. The statistical analysis was conducted using Stata 15.0 and Review Manager 5.3.

Results: A total of 15 studies with 6066 breast cancer patients were included in this meta-analysis. Pooled results indicated that positive expression of nestin was significantly associated with reduced breast cancer-specific survival (BCSS, univariate analysis, $\mathrm{HR}=2.11,95 \% \mathrm{Cl}[1.79,2.49], \mathrm{P}<0.00001$; multivariate analysis, $\mathrm{HR}=1.30,95 \% \mathrm{Cl}[1.06$, 1.60], $P=0.01)$, worse overall survival (OS, univariate analysis, $H R=1.88,95 \% \mathrm{Cl}[1.31,2.71], \mathrm{P}=0.0007$; multivariate analysis, $\mathrm{HR}=1.89,95 \% \mathrm{Cl}[1.34,2.67], \mathrm{P}=0.0003$ ) and poorer recurrence-free survival (univariate analysis, $\mathrm{HR}=2.60$, $95 \% \mathrm{Cl}[1.52,4.46], \mathrm{P}=0.0005)$, but not with distant metastasis-free survival in univariate analysis ( $\mathrm{P}>0.05)$. In addition, increased nestin expression was correlated with younger age, higher tumor grade, larger tumor size, positive blood vessel invasion and high vascular proliferation index, but not with lymph node metastasis or lymph vessel invasion. Nestin was preferentially expressed in invasive ductal carcinoma, triple-negative breast cancer and basal-like subtypes. Nestin expression was inversely associated with the expression of ER and PR, but not with HER-2. Conversely, nestin expression was positively correlated with the expression of basal-like markers CK5, P-cadherin and EGFR. Moreover, nestin expression was strongly associated with the presence of five basal-like profiles (BLP1-5).
\end{abstract}

Conclusions: This meta-analysis revealed the prognostic value and clinicopathological significance of nestin expression in breast cancer. Nestin is an independent prognostic factor for worse BCSS and OS of breast cancer patients. Nestin is also a valuable biomarker for unfavorable clinicopathological features and tumor angiogenesis of breast cancer. Therefore, nestin is a promising therapeutic target for malignant breast cancer, especially for TNBC and basallike phenotype.

Keywords: Nestin, Breast cancer, Clinicopathological characteristics, Prognosis, Meta-analysis

*Correspondence: xiekaixy@csu.edu.cn; kxie@houstonmethodist.org

${ }^{10}$ Department of General Surgery, The First Affiliated Hospital, Zhejiang

University School of Medicine, Hangzhou 310003, China

Full list of author information is available at the end of the article

(c) The Author(s) 2020. This article is licensed under a Creative Commons Attribution 4.0 International License, which permits use, sharing, adaptation, distribution and reproduction in any medium or format, as long as you give appropriate credit to the original author(s) and the source, provide a link to the Creative Commons licence, and indicate if changes were made. The images or other third party material in this article are included in the article's Creative Commons licence, unless indicated otherwise in a credit line to the material. If material is not included in the article's Creative Commons licence and your intended use is not permitted by statutory regulation or exceeds the permitted use, you will need to obtain permission directly from the copyright holder. To view a copy of this licence, visit http://creativeco mmons.org/licenses/by/4.0/. The Creative Commons Public Domain Dedication waiver (http://creativecommons.org/publicdomain/ zero/1.0/) applies to the data made available in this article, unless otherwise stated in a credit line to the data. 


\section{Background}

Breast cancer (BC) is one of the most commonly diagnosed malignant tumors in women worldwide and the leading cause of cancer-related female mortality [1]. Primarily derived from epithelial cells of the mammary gland, $\mathrm{BC}$ is a heterogeneous disease with diverse histological patterns and biological features which results in distinct clinical behaviors [2, 3]. Histopathological classification of $\mathrm{BC}$ was primarily based on immunohistochemical (IHC) detection of four molecular markers implicated in growth signaling pathways: estrogen receptor (ER), progesterone receptor (PR), human epidermal growth factor receptor 2 (HER2) and proliferation marker Ki-67 [4, 5]. In accordance with different expression patterns, $\mathrm{BC}$ can be classified into four subtypes: luminal $\mathrm{A}\left(\mathrm{ER}^{+}, \mathrm{PR}^{+}, \mathrm{HER} 2^{-}\right.$, low Ki-67 index),

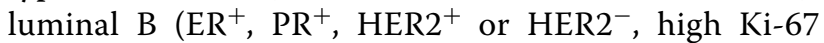
index), HER2-positive $\left(\mathrm{ER}^{-}, \mathrm{PR}^{-}, \mathrm{HER} 2^{+}\right)$and triplenegative breast cancer (TNBC, $\mathrm{ER}^{-}, \mathrm{PR}^{-}, \mathrm{HER} 2^{-}$) [6]. Moreover, gene expression profiling can more precisely and systematically sort $\mathrm{BC}$ into five intrinsic molecular subtypes: luminal A, luminal B, HER2-enriched, basallike and normal-like BC [7, 8]. Among these subtypes, basal-like subtype accounts for $15 \%$ of all invasive breast cancer and is characterized by highly aggressive behaviors, poor differentiation and lack of molecular targets for endocrine and anti-HER2 therapies [7-10]. Despite the dramatical improvements in the therapeutic strategies, including surgery, radiotherapy, chemotherapy and endocrine therapy, for fighting against $\mathrm{BC}$ in recent years, high rates of locoregional recurrence and metastasis of malignant breast cancer, especially TNBC and basal-like subtype, still greatly threatens the physical and mental health of women [11-15]. The relatively high cost of gene expression profiling limits its application in clinical practice [16]. Thus, identification of precise, low-cost and highly accessible biomarkers to accurately diagnose $\mathrm{BC}$ subtypes provides a novel approach to formulating individualized treatment regimens [17-19]. As a result, it is imperative to uncover the molecular mechanisms underlying the relapse and metastasis of malignant breast cancer and explore novel therapeutic targets to improve the management of breast cancer patients [20].

Several studies have recently targeted nestin as a promising diagnostic and prognostic marker of BC [2128]. Nestin is a type VI intermediate filament (IF) protein encoded by the NES gene and originally expressed in neural progenitor cells during embryonic development [29, 30]. Nestin expression is subsequently downregulated and replaced by tissue-specific IF proteins during cell differentiation in adults [31]. Apart from neural progenitor cells, nestin expression can be detected in immature or progenitor cells in some normal tissues as well. For instance, in the normal breast tissues, nestin is expressed in the basal/myoepithelial cells of the mammary gland [32].

Extensive studies have revealed that nestin is also a putative marker for cancer stem cells (CSCs) [33-36]. CSCs are hypothetically a small subpopulation of cancer cells that possess the capacity for self-renewal as well as drive tumorigenesis and therapeutic resistance [3739]. Aberrantly increased expression of nestin has been detected in various human malignant neoplasms, such as breast cancer [32], gliomas [35], melanomas [40], prostate cancer [36], gastrointestinal cancer [41, 42] and other cancer types [43-45]. Moreover, the prognostic value of nestin for patients with cancer has been widely validated in various solid tumors, such as epithelial ovarian cancer [46], non-small cell lung cancer [47], glioma [48, 49], etc. However, the prognostic and clinicopathological value of nestin in breast cancer patients remained controversial. Some studies have demonstrated the strong link between increased nestin expression and poor prognosis of breast cancer patients [20, 21, 23-26, 28, 50-52]. Conversely, some other studies revealed no significant association between nestin expression and survival outcomes of breast cancer patients [22, 27]. To address these discrepancies, we performed this meta-analysis to systematically determine the prognostic and clinicopathological impact of nestin on patients with breast cancer.

\section{Materials and methods}

\section{Search strategies}

Meta-analysis was performed in accordance with the Preferred Reporting Items for Systematic Review and Meta-Analysis (PRISMA) Statement [53]. A systematic literature search of the electronic databases PubMed, EMBASE, Web of Science, the Cochrane Library, China National Knowledge Infrastructure (CNKI), and the Wangfang Data up to October 2019 was performed, without any limitation of origin and languages. The studies were identified by a random combination of the following terms: "nestin", "breast neoplasm OR breast tumor OR breast cancer OR breast carcinoma", "prognosis OR survival OR outcome". In addition, the reference lists of the retrieved studies and review articles were manually searched for potentially relevant studies.

\section{Selection criteria}

The studies included in the present meta-analysis were randomized controlled trials (RCTs) or observational studies (case-control or cohort) that evaluated the association of nestin expression with clinicopathological features or prognosis of patients with breast cancer. Studies were eligible if they met the following criteria: (a) studies were published 
as original articles with full text available; (b) definitive diagnosis of breast cancer was confirmed by histopathological examination; (c) nestin expression was detected by an immunohistochemistry (IHC) method or quantitative real-time polymerase chain reaction (qRT-PCR) method based on breast cancer tissues (instead of serum or other specimens), and (d) the correlation of nestin expression with clinicopathological features or prognostic outcomes was analyzed. Studies were excluded from the analyses based on the following criteria: (a) articles were published as reviews, abstracts, case reports, letters or comments; (b) studies were not associated with the topic of the interest; (c) data were obtained from cell lines or animal models; (d) data were analyzed based on public databases; (e) data for estimating the relationship between nestin expression and survival outcomes or clinicopathological features were insufficient, and (f) data were from duplicated studies based on the same or similar patient population.

\section{Data extraction}

Two investigators (XYZ and WTG) independently reviewed the included studies and extracted prognostic or clinicopathological data. Discrepancies in data extraction were resolved by a third investigator (KX). The following data were collected from each included study in a predefined table: the name of first author, year of publication, country, cancer types, number of patients, age, follow-up periods, detection method, cut-off value, clinicopathological parameters and prognostic outcomes (breast cancer-specific survival [BCSS], overall survival [OS], distant metastasis-free survival [DMFS], recurrence-free survival [RFS] and progression-free survival [PFS]). Since some studies displayed the survival data indirectly with a Kaplan-Meier curve, the software Engauge Digitizer version 12 (http://markummitc hell.github.io/engauge-digitizer/) was applied to digitize and extract survival data. Because the cut-off value for nestin expression varied among different studies, we defined the nestin-positive group according to the original articles.

\section{Qualitative assessment}

The methodological quality of included studies was assessed by two independent viewers (XYZ and WTG) using the Newcastle-Ottawa Quality Assessment Scale (NOS) (Additional file 1: Table S1). According to the guideline, NOS scores of $\geq 6$ were determined to be highquality studies.

\section{Statistical analysis}

All statistical analyses were performed by using the software Review Manager 5.3.5 (Cochrane Collaboration, Copenhagen, Denmark) and STATA 15.0 (Stata Corporation, College Station, TX, USA). The odds ratio (OR) with 95\% confidence interval (CI) were calculated to assess the correlation between nestin expression and clinicopathological characteristics of breast cancer. $\mathrm{P}<0.05$ were considered as statistical significance. To evaluate the prognostic effect of nestin expression on patients with breast cancer, pooled hazard ratio (HR) with 95\% CI of survival outcomes were calculated. If a pooled HR is larger than 1, it reflects a worse prognosis for patients with positive nestin expression, while a pooled HR smaller than 1 represents a favorable prognosis. Heterogeneity among studies was assessed by the Chi-square $\left(\mathrm{X}^{2}\right)$ test and $\mathrm{I}^{2}$ test. When there was no significant heterogeneity $\left(\mathrm{P}>0.05\right.$ or $\left.\mathrm{I}^{2}<50 \%\right)$, the fixed-effects model was employed; otherwise, the random-effects model was used. Sensitivity analyses were performed to examine the robustness of pooled data. Begg's and Egger's tests were conducted to assess the potential publication bias.

\section{Results}

\section{Description of studies}

Detailed steps of literature search and study selection were shown in a flow diagram [53] (Fig. 1). A total of 566 studies were initially retrieved with search strategies described above. In line with the selection criteria, 441 articles were left after duplicated records removed. After screening the titles and abstracts of identified articles, 393 articles were excluded on account of irrelevant topics, conference abstracts or cell and animal models. The remaining 48 articles were reviewed in full text, 33 articles were excluded, including 3 reviews, 29 studies without clinicopathological or survival data, and one study based on data from the public database. A total of 15 studies with were 6066 patients eventually included in the present meta-analysis. The main characteristics of eligible studies in the qualitative and quantitative synthesis were summarized in Table 1.

\section{Correlation between nestin expression and breast cancer-specific survival}

Six studies [21, 23-27] were included in the univariate analysis of the impact of nestin expression on breast cancer-specific survival (BCSS) (Table 1). As Asleh et al. [21] described, BCSS was defined as the time from diagnosis to either death by breast cancer or last follow up. The pooled result indicated that nestin expression was significantly associated with worse BCSS (pooled $\mathrm{HR}=2.11,95 \%$ CI $\left.[1.79,2.49], \mathrm{P}<0.00001, \mathrm{I}^{2}=0 \%\right)$ (Fig. 2a). Moreover, three studies [23, 26, 27] investigated the correlation between nestin expression and BCSS of patients stratified by lymph node status. The pooled analysis based on univariate data showed the same result both in lymph node-negative group (pooled $\left.\mathrm{HR}=2.59,95 \% \mathrm{CI}[1.37,4.89], \mathrm{P}=0.003, \mathrm{I}^{2}=0 \%\right)$ and lymph node-positive group (pooled $\mathrm{HR}=2.37$, 95\% CI 


\section{PRISMA 2009 Flow Diagram}

Records identified through database

searching $(n=566)$

1) PubMed: $n=63$

2) Embase: $n=322$

3) Web of Science: $n=175$

4) Cochrane Library: $n=6$
Additional records identified through other sources

$(n=0)$

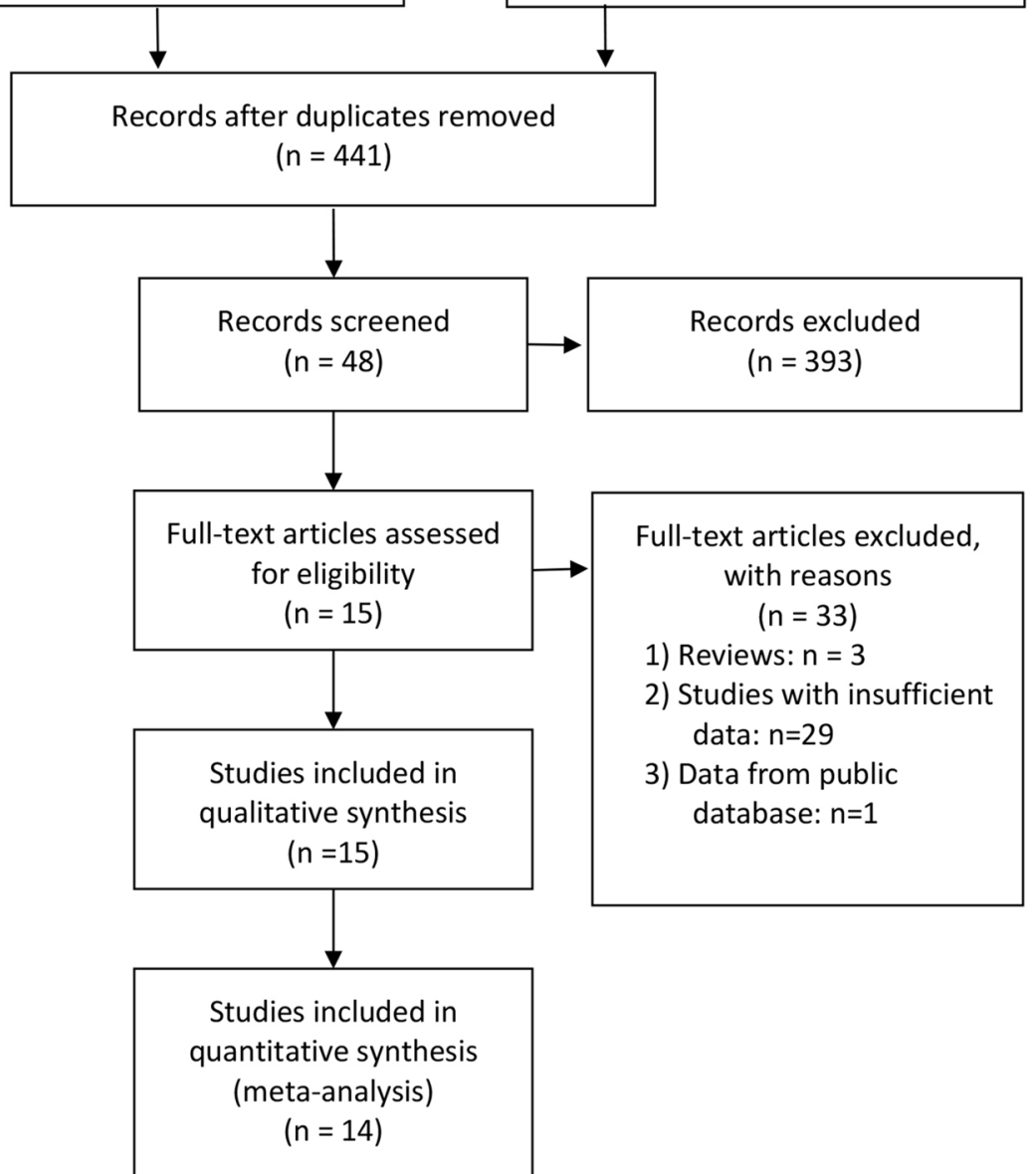

Fig. 1 Flow diagram of the literature search and study selection in the meta-analysis

[1.37, 4.11], $\mathrm{P}=0.002, \mathrm{I}^{2}=33.6 \%$ ) (Fig. 2b). Subgroup analysis of BCSS on the basis of univariate data was conducted and stratified in terms of source of data, including data directly obtained from articles and data calculated from Kaplan-Meier curves. Pooled results revealed that increased nestin expression in patients with breast cancer predicted worse BCSS in both subgroups (Direct data group: pooled $\mathrm{HR}=2.02$, 95\% CI $[1.68,2.43], \mathrm{P}=0.01$,
$\mathrm{I}^{2}=0 \%$; Calculated data group: pooled $\mathrm{HR}=2.48,95 \%$ CI $[1.75,3.52], \mathrm{P}=0.01, \mathrm{I}^{2}=0 \%$ ) (Fig. 2c). Additionally, a multivariate analysis of two studies [21,24] demonstrated the similar result (pooled HR $=1.30,95 \%$ CI $[1.06,1.60]$, $\mathrm{P}=0.01, \mathrm{I}^{2}=47.4 \%$ ) (Table 1, Fig. 2d). 


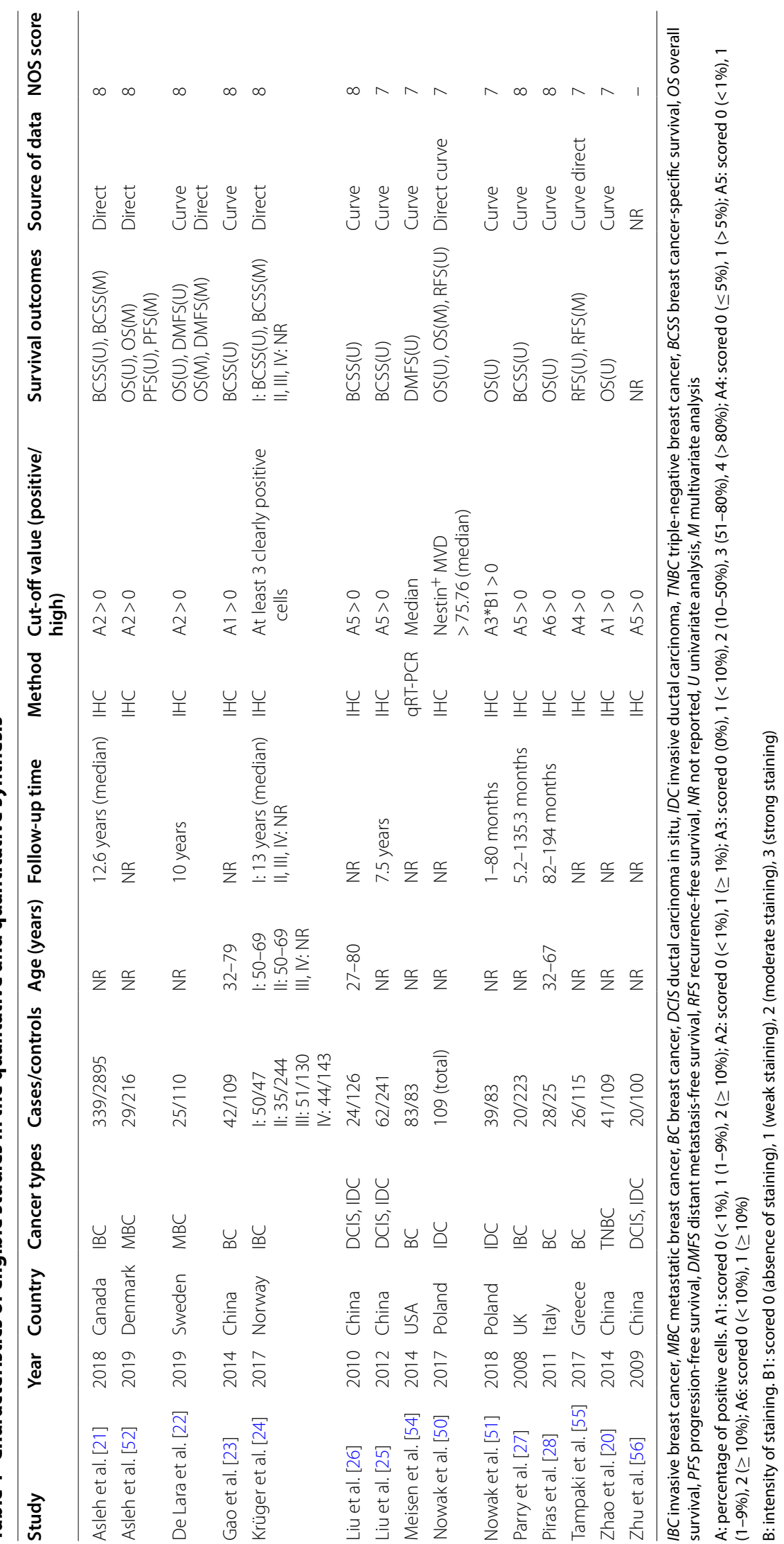


Correlation between nestin expression and overall survival A pooled analysis of six studies [20, 22, 28, 50-52] reported overall survival (OS) data using univariate analysis (Table 1$)$. With slight heterogeneity $(\mathrm{P}=0.055$, $\left.\mathrm{I}^{2}=53.8 \%\right)$, a random-effects model showed increased nestin expression in patients with breast cancer predicted reduced OS (pooled $\mathrm{HR}=1.88,95 \%$ CI [1.31, 2.71], $\mathrm{P}=0.0007$ ) (Fig. 2e). Stratified by source of data, subgroup analysis of OS based on univariate data demonstrated that nestin expression was significantly correlated with $\mathrm{OS}$ in calculated data group (pooled $\mathrm{HR}=1.76$, 95\% CI $\left.[1.14,2.73], \mathrm{P}=0.01, \mathrm{I}^{2}=49.4 \%\right)$, but not with OS in direct data group due to substantial heterogeneity between two included studies (pooled $\mathrm{HR}=2.51,95 \% \mathrm{CI}$ $\left.[0.80,7.88], \mathrm{P}=0.12, \mathrm{I}^{2}=78.7 \%\right)$. Furthermore, a pooled analysis of three studies $[22,50,52]$ based on multivariate data also exhibited the same result (pooled $\mathrm{HR}=1.89$, 95\% CI $[1.34,2.67], \mathrm{P}=0.0003, \mathrm{I}^{2}=26 \%$ ) (Table 1, Fig. $2 \mathrm{~g})$.

\section{Correlation between nestin expression and other survival outcomes}

Two studies [22, 54] including 301 patients, investigated the correlation between nestin expression and distant metastasis-free survival (DMFS) based on univariate data (Table 1). As Lara et al. [22] described, DMFS refers to the time from the initial diagnosis of the primary breast carcinoma to distant metastasis. With moderate heterogeneity $\left(\mathrm{P}=0.079, \mathrm{I}^{2}=67.6 \%\right)$, a random-effects model showed no significant association between nestin expression and DMFS (pooled HR $=1.40,95 \%$ CI $[0.74,2.64]$, $\mathrm{P}=0.30$ ) (Fig. 2h). Moreover, the study by Lara et al. [22] revealed that nestin is neither an independent prognostic factor for DMFS in multivariate analysis $(\mathrm{HR}=1.52,95 \%$ CI $[0.75,3.06], \mathrm{P}=0.25)$.

Another two studies [50, 55] with 249 patients were included in the univariate analysis of the correlation of nestin expression with recurrence-free survival (RFS) (Table 1). RFS is defined as the time from the initial diagnosis of the primary breast carcinoma to recurrence. The pooled result demonstrated that increased nestin expression predicts poorer RFS (pooled $\mathrm{HR}=2.60,95 \% \mathrm{CI}$ $[1.52,4.46], \mathrm{P}=0.0005, \mathrm{I}^{2}=0 \%$ ) (Fig. 2h). However, the study by Tampaki et al. [55] reported that nestin is not an independent prognostic factor for RFS in multivariate analysis $(\mathrm{HR}=1.238,95 \% \mathrm{CI}[0.512,2.989], \mathrm{P}=0.636)$.
In addition, Asleh et al. [52] also reported the impact of nestin expression on progression-free survival (PFS). Increased expression of nestin was associated with reduced PFS based on univariate data $(\mathrm{HR}=1.65,95 \% \mathrm{CI}$ $[1.04,2.63], \mathrm{P}=0.03)$. However, no significant association was noted between nestin expression and PFS in multivariate analysis $(\mathrm{HR}=1.26,95 \% \mathrm{CI}[0.75,2.11], \mathrm{P}=0.39)$.

\section{Correlation between nestin expression and clinicopathological parameters}

A total of three studies [25, 26, 56] with 590 patients investigated the association between nestin expression and age. Pooled result revealed that nestin was preferentially expressed in patients younger than 35 years old (Age $>35$ vs. Age $<35$, pooled $\mathrm{OR}=0.45,95 \%$ CI $[0.26$, 0.80 ], $\mathrm{P}=0.006, \mathrm{I}^{2}=0 \%$ ) (Fig. 3a). Additionally, the study by Asleh et al. [21] including 3234 patients demonstrated that nestin expression rate was higher in patients younger than 61 years old (Age $>60$ vs. Age $\leq 60$, OR $=0.57,95 \%$ CI $[0.45,0.72], \mathrm{P}<0.00001)$. These results indicated nestin was closely associated with a younger age for the onset of BC.

To confirm the correlation between nestin expression and TMN staging (histological grade, tumor size and lymph node status), a pooled analysis of thirteen datasets from ten studies $[21-28,55,56]$ showed that nestin expression was significantly associated with higher tumor grade (grade III vs. grade I-II, pooled OR $=4.90,95 \%$ CI $[2.73,8.79], \mathrm{P}<0.00001, \mathrm{I}^{2}=84 \%$ ) (Fig. 3b) and larger tumor size $(\mathrm{T}>2 \mathrm{~cm}$ vs. $\mathrm{T}<2 \mathrm{~cm}$, pooled $\mathrm{OR}=1.30,95 \%$ CI $[1.09,1.55], \mathrm{P}=0.004, \mathrm{I}^{2}=35 \%$ ) (Fig. 3c), but not with lymph node metastasis $\left(\mathrm{N}_{+}\right.$vs. $\mathrm{N}_{0}$, pooled $\mathrm{OR}=0.99$, $95 \%$ CI $[0.69,1.42], \mathrm{P}=0.96, \mathrm{I}^{2}=64 \%$ ) (Fig. 3d).

Nestin has recently drawn attention as a marker for tumor angiogenesis. Eight datasets from five studies [21, $23,24,26,27]$ were included in investigating the correlation of nestin expression with three angiogenesisrelated variables blood vessel invasion (BVI), lymph vessel invasion (LVI) and vascular proliferation index (VPI). As Krüger et al. [24] described, VPI was defined as the proportion of vessels with proliferating endothelial cells. Pooled results demonstrated that nestin expression was significantly associated with positive BVI (pooled OR $=2.60,95 \%$ CI $[1.36,4.97], \mathrm{P}=0.004, \mathrm{I}^{2}=0 \%$ ) (Fig. 3e) and high VPI (pooled OR $=3.00,95 \%$ CI $[1.91$, 4.71], $\mathrm{P}<0.00001, \mathrm{I}^{2}=0 \%$ ) (Fig. 3f), but not with LVI

\footnotetext{
(See figure on next page.)

Fig. 2 Forest plots of the correlation of nestin expression with survival outcomes. a The correlation of nestin expression with BCSS in univariate analysis; b The correlation of nestin expression with BCSS stratified by lymph node status in univariate analysis; c Subgroup analysis of BCSS based on univariate data stratified by source of data; $\mathbf{d}$ The correlation of nestin expression with BCSS in multivariate analysis; e The correlation of nestin expression with OS in univariate analysis; $\mathbf{f}$ Subgroup analysis of OS based on univariate data stratified by source of data; $\mathbf{g}$ The correlation of nestin expression with OS in multivariate analysis; $\mathbf{h}$ The correlation of nestin expression with DMFS and RFS in univariate analysis
} 
a Study ID Asleh Ket al (2018) Gao NN et al (2014) Krüger K et al-I (2017) Liu CG et al (2010) Liu CG et al (2012) Parry S et al (2008) Overall (I-squared $=0.0 \%, p=0.614$ ) BCSS (univariate analysis)

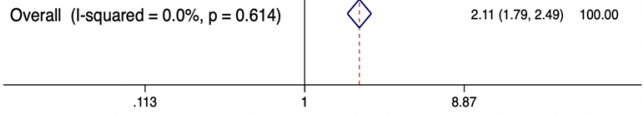

C

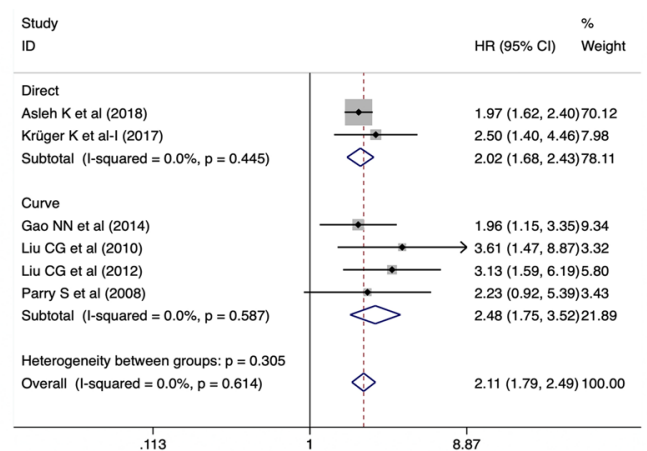

e Study

ID

OS (univariate analysis)

Asleh Ket al (2019)

De Lara S et al (2019)

Nowak A et al (2017)

Nowak A et al (2018)

Piras F et al (2011)

Zhao ZW et al (2014)

Overall (I-squared $=53.8 \%, p=0.055)$

NOTE: Weights are from random effects analysis

.0748

OS (multivariate analysis)

g

Study

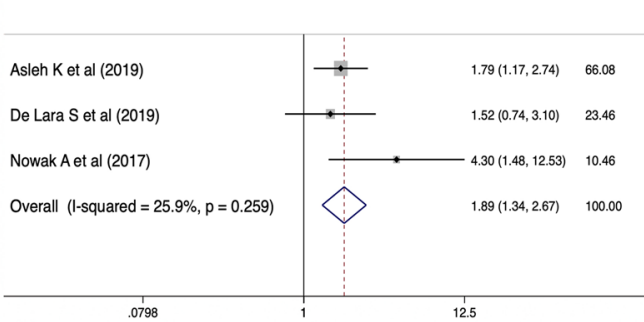

$1.09(0.70,1.68) \quad 22.31$

$4.96(1.84,13.37) \quad 9.57$

$2.35(1.14,4.84) \quad 14.32$

$2.07(1.00,4.28) \quad 14.23$

$2.36(1.23,4.52) \quad 16.01$

$1.88(1.31,2.71) \quad 100.00$ b BCSS stratified by lymph node status (univariate analysis) Study

Lymph node negative

Gao NN et al (2014)

Liu CG et al (2010)

Parry $S$ et al (2008)

Subtotal $(1$-squared $=0.0 \%, p=0.936) \quad \longrightarrow \quad 2.59(1.37,4.89) \quad 100.00$

Lymph node positive

Gao NN et al (2014)

Liu CG et al (2010)

Parry etal(2008) 10

Subtotal (1-squared $=33.6 \%, \mathrm{p}=0.222) \quad \longrightarrow \quad 2.37(1.37,4.11) \quad 100.00$

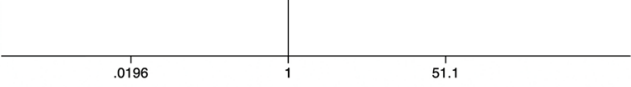

d

BCSS (multivariate analysis)

Study

ID

HR $(95 \%$ Cl) Weight

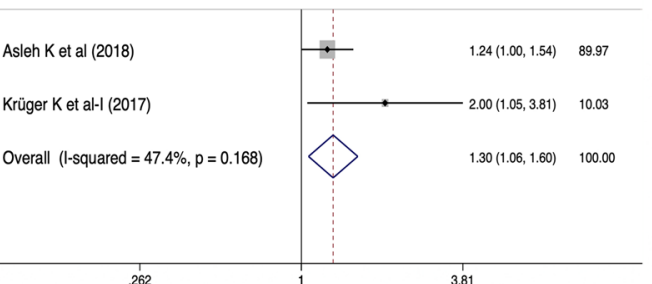

Subgroup analysis of OS

f study

Study
ID

HR $(95 \% \mathrm{Cl}) \quad$ Weight

Direct

Asleh Ket al (2019)

Asleh Kowak al (2019)

Nowak A

Subtotal (1-squared $=78.7 \%, p=0.030)$

Curve

De Lara S et al (2019)

Nowak A et al (2018)

Piras $\mathrm{F}$ et al (2011)

Zhao ZW et al (2014)

Subtotal (I-squared $=49.4 \%, p=0.115)$

Overall (1-squared $=53.8 \%, p=0.055$ )

NOTE: Weights are trom rendom effects analysis

.0748

DMFS and RFS (univariate analysis)

h

Study

$\mathrm{HR}(95 \% \mathrm{Cl}) \quad$ Weigh

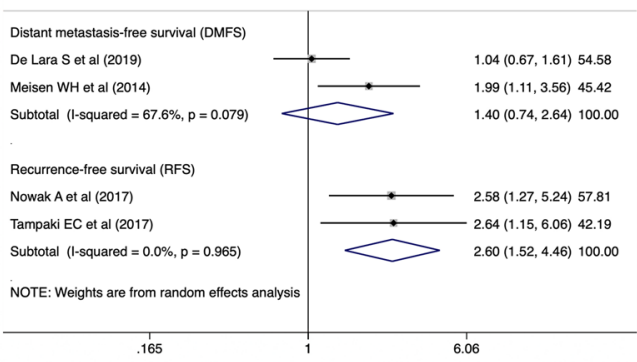




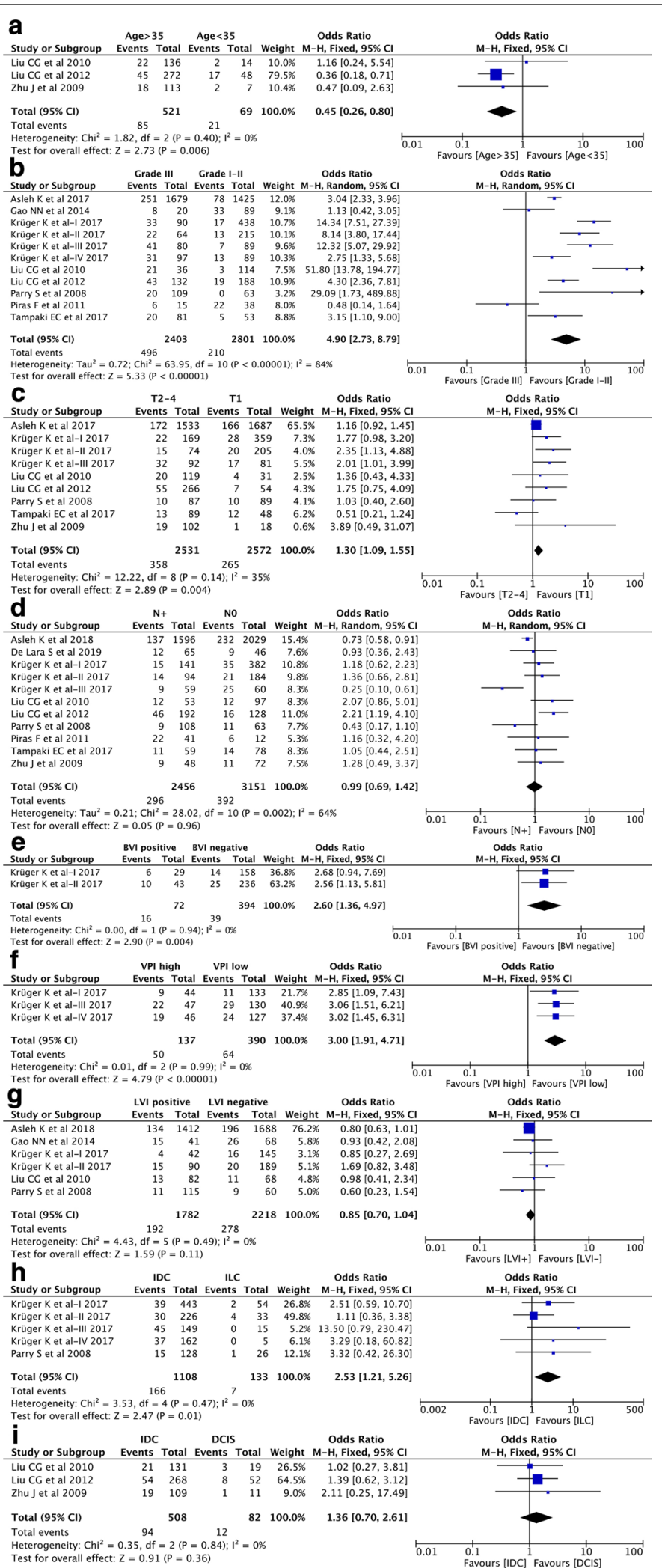

Fig. 3 Forest plots of the correlation between nestin expression and clinicopathological parameters. a Age (age $>35$ vs. age < 35 ); $\mathbf{b}$ TNM stage (grade III vs. grade I-II); $\mathbf{c}$ Tumor size ( $\mathrm{T}_{2-4}$ Vs. $\left.\mathrm{T}_{1}\right)$; $\mathbf{d}$ Lymph node metastasis $\left(\mathrm{N}_{+} \mathrm{Vs} . \mathrm{N}_{0}\right)$; e BVI (positive vs. negative); f VPI (high vs. low); $\mathbf{g} \mathrm{LVI}$ (positive vs. negative); $\mathbf{h} I D C$ Vs. ILC; $\mathbf{i} I D C$ vs. DCIS 
Fig. 4 Forest plots of the correlation between nestin expression and IHC markers. a ER (positive vs. negative); b PR (positive vs. negative); c HER2 (positive vs. negative); d Ki-67 (high vs. low); e TNBC vs. Non-TNBC; $\mathbf{f}$ CK5 (positive vs. negative); $\mathbf{g}$ P-cadherin (positive vs. negative); h EGFR (positive vs. negative); i BLP1 (present vs. absent); $\mathbf{j}$ BLP2 (present vs. absent); $\mathbf{k}$ BLP3 (present vs. absent); I BLP4 (present vs. absent); $\mathbf{m}$ BLP5 (present vs. absent); $\mathbf{n}$ p53 (positive vs. negative); o FOXA1 (positive vs. negative)

(positive vs. negative, pooled $\mathrm{OR}=0.85,95 \% \mathrm{CI}[0.70$, 1.04], $\mathrm{P}=0.11, \mathrm{I}^{2}=0 \%$ ) (Fig. 3g).

Invasive ductal carcinoma (IDC) and invasive lobular carcinoma (ILC) are the most common histological types of invasive breast cancer (IBC) [57]. Five datasets from two studies [24, 27] investigated the differential expression of nestin between IDC and ILC. Pooled result revealed an increased expression level of nestin in IDC when compared with ILC (pooled OR $=2.53,95 \%$ CI $[1.21,5.26], \mathrm{P}=0.01, \mathrm{I}^{2}=0 \%$ ) (Fig. 3h). Moreover, three studies $[25,26,56]$ were included in the comparison of nestin expression between IDC and ductal carcinoma in situ (DCIS). It revealed that there was no significant difference in nestin expression between IDC and DCIS (IDC vs. DCIS, pooled OR $=1.36,95 \%$ CI $[0.70,2.61]$, $\mathrm{P}=0.36, \mathrm{I}^{2}=0 \%$ ) (Fig. 3i).

\section{Correlation between nestin expression and immunohistochemical markers}

A total of 11 datasets from 8 studies [21-24, 26-28, 56] investigated the correlation of nestin expression with the expression of ER, PR, HER-2 and Ki-67. The pooled results showed that nestin expression was negatively associated with the expression of ER (pooled OR $=0.12$, 95\% CI [0.08, 0.19], $\mathrm{P}<0.00001, \mathrm{I}^{2}=70 \%$ ) (Fig. 4a) and $\mathrm{PR}$ (pooled OR $=0.19,95 \%$ CI $[0.12,0.30], \mathrm{P}<0.00001$, $\mathrm{I}^{2}=57 \%$ ) (Fig. $4 \mathrm{~b}$ ). Besides, nestin expression was positively correlated with high expression of cell proliferation marker Ki-67 (pooled OR $=6.00,95 \%$ CI $[3.28,10.96]$, $\mathrm{P}<0.00001, \mathrm{I}^{2}=81 \%$ ) (Fig. $4 \mathrm{~d}$ ). However, there was no significant association between the expression of nestin and HER-2 status (pooled OR $=0.71,95 \%$ CI $[0.44,1.15]$, $\mathrm{P}=0.17, \mathrm{I}^{2}=51 \%$ ) (Fig. 4c). More importantly, nine studies with 4335 patients $[21-23,25-28,55,56]$ compared the nestin expression between triple negative breast cancer (TNBC) and non-triple negative breast cancer. With moderate heterogeneity $\left(\mathrm{P}=0.007, \mathrm{I}^{2}=62 \%\right)$, the pooled analysis in random-effects model revealed nestin was preferentially expressed in TNBC than that in non-TNBC (pooled OR=9.34, 95\% CI [5.92, 14.73], $\mathrm{P}<0.00001$ ) (Fig. 4e). Additionally, the correlation between the expression nestin and some other biomarkers, such as p53 and forkhead box protein A1 (FOXA1), was also reported in several studies [22, 24, 26, 27]. Nestin

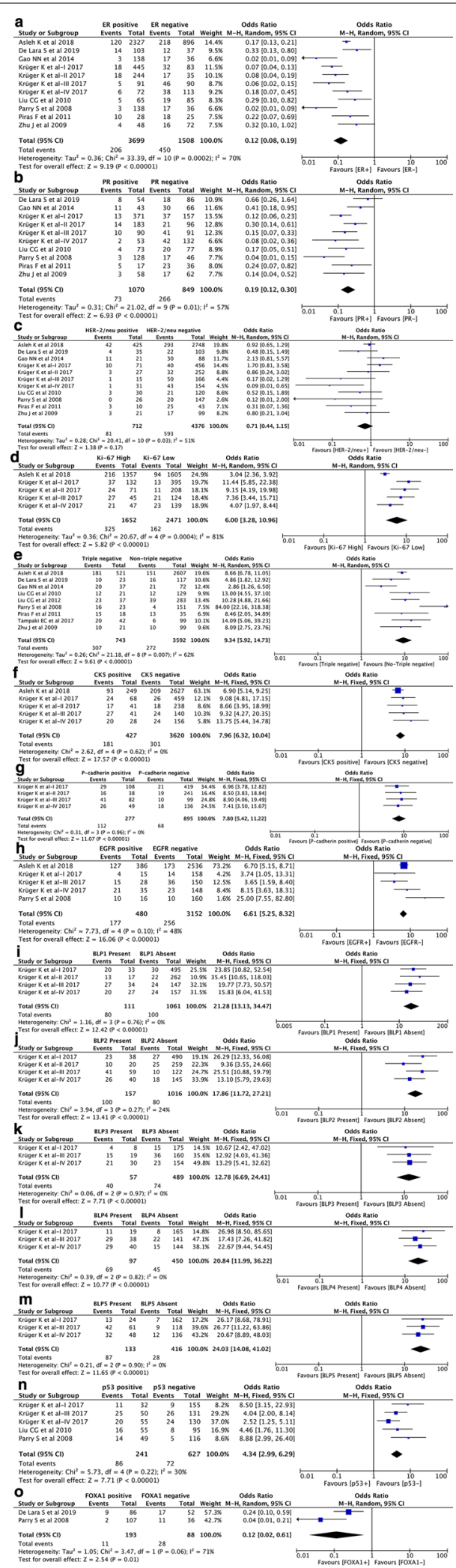




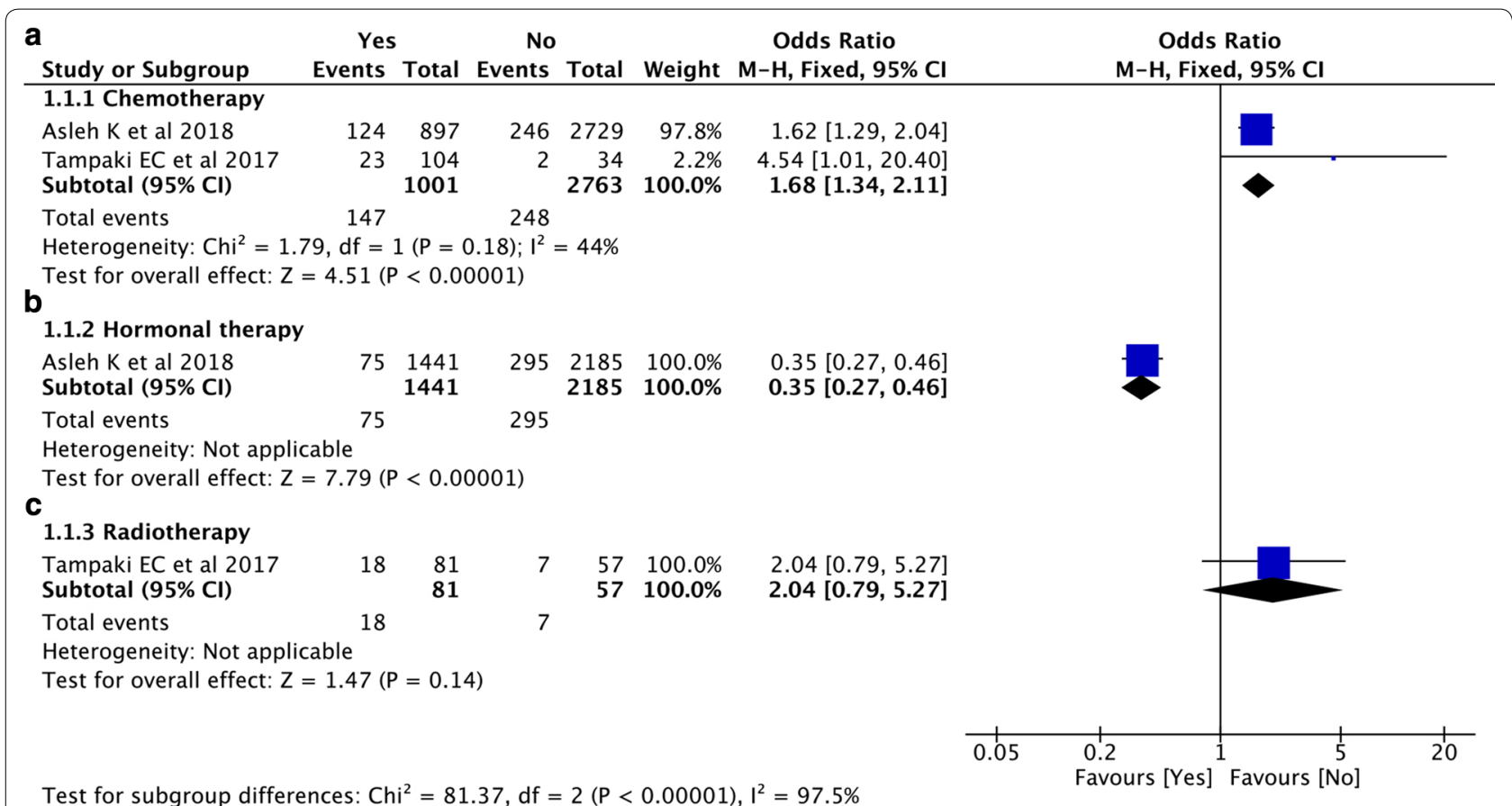

Fig. 5 Forest plots of the correlation between nestin expression and adjuvant systemic therapies. a Chemotherapy; b Hormonal therapy; c Radiotherapy

expression revealed significant association with positive p53 nuclear expression (pooled OR $=4.34,95 \%$ CI [2.99, 6.29], $\mathrm{P}<0.00001, \mathrm{I}^{2}=30 \%$ ) (Fig. $4 \mathrm{n}$ ) and negative expression of FOXA1 (pooled OR $=0.12,95 \%$ CI $[0.02,0.61]$, $\mathrm{P}=0.01, \mathrm{I}^{2}=71 \%$ ) (Fig. 4o).

Three studies with six datasets [21, 24, 27] were included in the analysis of the association of nestin expression with basal-like markers cytokeratin 5 (CK5), P-cadherin and epidermal growth factor receptor (EGFR). The pooled results demonstrated that nestin expression was significantly correlated with the positive expression of CK5 (pooled OR $=7.96,95 \% \mathrm{CI}$ [6.32, 10.04], $\mathrm{P}<0.00001, \mathrm{I}^{2}=0 \%$ ) (Fig. 4f), P-cadherin (pooled $\mathrm{OR}=7.80,95 \%$ CI $[5.42,11.22], \mathrm{P}<0.00001$, $\mathrm{I}^{2}=0 \%$ ) (Fig. 4g), and EGFR (pooled OR $=6.61,95 \% \mathrm{CI}$ [5.25, 8.32], $\mathrm{P}<0.00001, \mathrm{I}^{2}=48 \%$ ) (Fig. 4h). Moreover, four series (series I-IV) from the study by Krüger et al. [24] with 1172 breast cancer patients also investigated the correlation of nestin expression with basal-like profiles (BLP). As Krüger et al. [24] described, five basal-like profiles (BLPs) were defined based on the combination of different IHC markers (BLP1: ER ${ }^{-}$, HER2 ${ }^{-}$, CK5+; BLP2: $\mathrm{ER}^{-}, \mathrm{HER}^{-}{ }^{-}, \mathrm{P}$-cadherin+; BLP3: $\mathrm{ER}^{-}, \mathrm{HER} 2^{-}$, EGFR+; BLP4: $\mathrm{ER}^{-}, \mathrm{HER}^{-}$, CK5+ and/or EGFR+; BLP5: $\mathrm{ER}^{-}$, HER2 $^{-}$, CK5+ and/or P-cadherin+ and/or EGFR+). Among these five BLPs, BLP4 is regarded as a core basal phenotype (CBP). The pooled results revealed that nestin expression was strongly correlated with the presence of BLPs (BLP1: pooled OR $=21.28,95 \%$ CI [13.13, 34.47], $\mathrm{P}<0.00001, \mathrm{I}^{2}=0 \%$; $\mathrm{BLP} 2$ : pooled $\mathrm{OR}=17.86$, 95\% CI $[11.72,27.21], \quad \mathrm{P}<0.00001, \mathrm{I}^{2}=24 \%$; BLP3: pooled $\mathrm{OR}=12.78,95 \%$ CI $[6.69,24.41], \mathrm{P}<0.00001$, $\mathrm{I}^{2}=0 \%$; BLP4: pooled $\mathrm{OR}=20.84,95 \%$ CI $[11.99,36.22]$, $\mathrm{P}<0.00001, \mathrm{I}^{2}=0 \%$; BLP5: pooled $\mathrm{OR}=24.03,95 \% \mathrm{CI}$ [14.08, 41.02], $\mathrm{P}<0.00001, \mathrm{I}^{2}=0 \%$ ) (Fig. $4 \mathrm{i}-\mathrm{m}$ ). Furthermore, the study by Asleh et al. including 3128 patients [21] indicated that nestin was predominantly expressed in core basal subtype than that in non-core basal subtype $(\mathrm{OR}=10.59,95 \% \mathrm{CI}[8.08,13.88], \mathrm{P}<0.00001)$.

\section{Correlation between nestin expression and adjuvant systemic therapies}

Two studies [21, 55] with 3764 patients investigated the correlation between nestin expression and chemotherapy. Pooled result indicated an increased expression level of nestin in patients treated with chemotherapy than that in patients without receiving chemotherapy (pooled $\mathrm{OR}=1.68,95 \%$ CI $[1.34,2.11], \mathrm{P}<0.00001$, $\mathrm{I}^{2}=44 \%$ ) (Fig. 5a). Besides, the study by Asleh et al. [21] also revealed that expression level of nestin was down-regulated in patients treated with hormonal therapy (Tamoxifen) than that in patients without receiving hormonal therapy $(\mathrm{OR}=0.35,95 \% \mathrm{CI}[0.27,0.46]$, $\mathrm{P}<0.00001$ ) (Fig. 5b). However, the study by Tampaki 


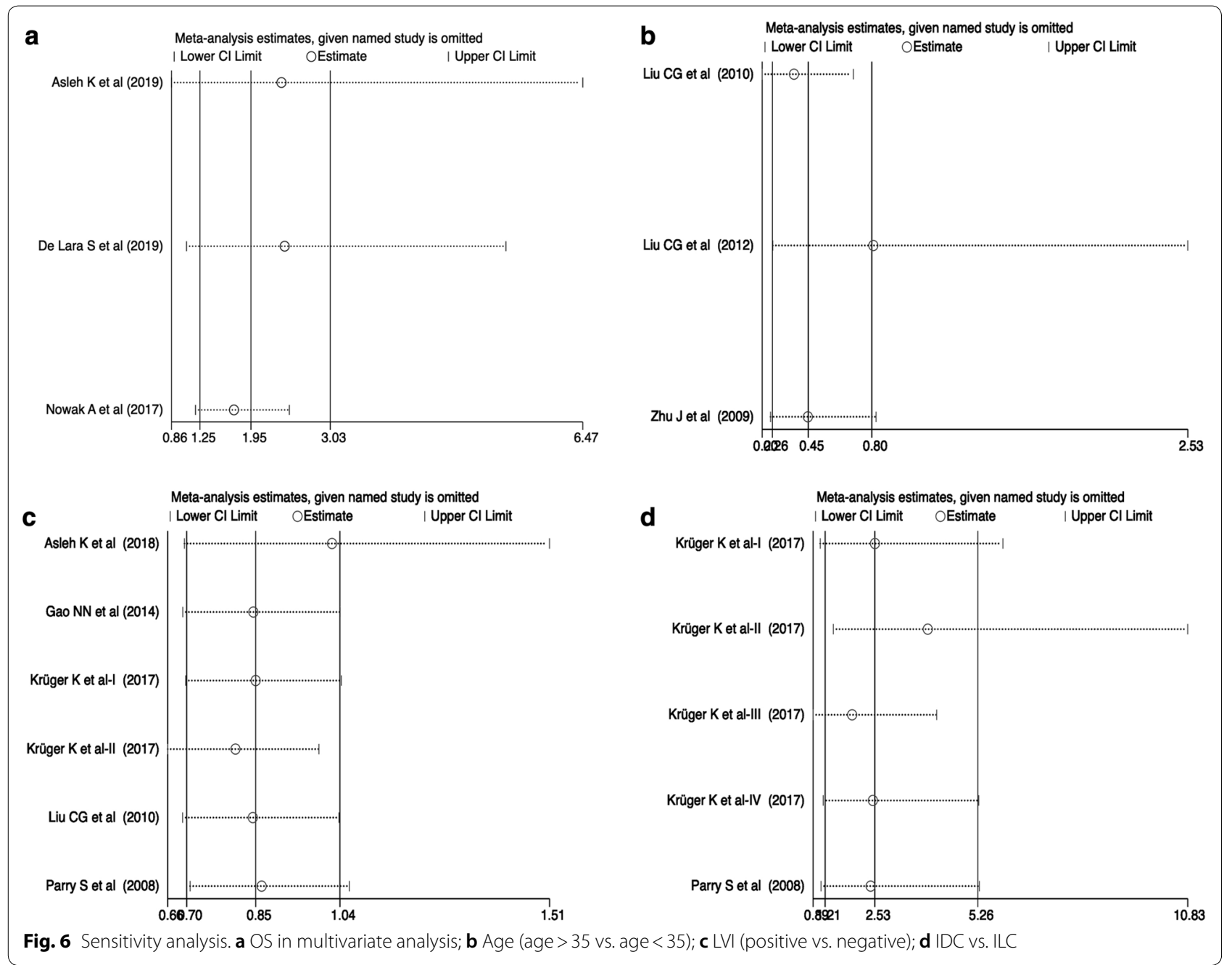

et al. [55] showed no significant difference in nestin expression between patients with radiotherapy than that in patients without receiving radiotherapy $(\mathrm{OR}=2.04$, 95\% CI [0.79, 5.27], P = 0.14) (Fig. 5c).

\section{Sensitivity analysis and publication bias}

Sensitivity analysis was performed to validate the stability of the pooled studies (Fig. 6, Additional file 1: Fig. S1). As shown in Table 2, no individual study could statistically significantly alter the combined results of survival outcomes and clinicopathological parameters but the study by Asleh et al. [52], the study by Liu et al. [25] and Series II from the study by Krüger et al. [24], which altered the pooled results of the correlation of nestin expression with OS (multivariate analysis), age, and LVI, respectively (Fig. 6a-c). Besides, Series III from the study by Krüger et al. [24] can affect the pooled OR of nestin expression between IDCs and ILCs (Fig. 6d). More eligible studies should be added in these pooled analyses to draw stable conclusions.
Potential publication bias of survival outcomes and clinicopathological parameters was evaluated using Begg's test (Fig. 7a-c, Additional file 2: Fig. S2) and Egger's test (Fig. 7d-f, Additional file 3: Fig. S3). As shown in Table 2, P values assessed by Begg's test and Egger's test were all greater than 0.05 except the evidence of significant publication bias $(\mathrm{P}<0.05)$ in three pooled studies (Fig. 7). Therefore, the trim and fill method was utilized to evaluate the potential impacts of publication bias. For the pooled analysis of the association of nestin expression with OS of breast cancer (univariate analysis, Egger's test, $\mathrm{P}=0.018$ ), a filled funnel plot was generated by trim and fill analysis including two imputed studies, and the meta-analysis incorporating these two imputed studies demonstrated the similar result (univariate analysis, adjusted $\mathrm{HR}=1.575,95 \%$ CI [1.089-2.279], $\mathrm{P}=0.016$ ) (Fig. 8a). Similarly, trim and fill analysis including three imputed studies generated a symmetrical funnel plot for the pooled analysis 
Table 2 Sensitivity analysis and publication bias

\begin{tabular}{|c|c|c|c|c|}
\hline & \multicolumn{2}{|l|}{ Sensitivity analysis } & \multicolumn{2}{|c|}{ Publication bias (P value) } \\
\hline & HR/OR fluctuation & $95 \% \mathrm{Cl}$ fluctuation & Begg's test & Egger's test \\
\hline \multicolumn{5}{|c|}{ Nestin expression and survival outcomes } \\
\hline $\operatorname{BCSS}(U)$ & $2.061-2.488$ & $1.741-3.357$ & 0.060 & 0.065 \\
\hline BCSS(M) & $1.240-2.000$ & $1.000-3.810$ & 1.000 & - \\
\hline OS(U) & $1.648-2.117$ & $1.202-3.386$ & 0.260 & 0.018 \\
\hline OS(M) & $1.715-2.362$ & $0.862-6.474$ & 1.000 & 0.536 \\
\hline $\operatorname{DMFS}(U)$ & $1.040-1.993$ & $0.674-3.564$ & 1.000 & - \\
\hline $\operatorname{RFS}(U)$ & $2.575-2.640$ & $1.150-6.061$ & 1.000 & - \\
\hline \multicolumn{5}{|c|}{ Nestin expression and clinicopathological parameters } \\
\hline Age (> 35 vs. <35) & $0.375-0.809$ & $0.200-2.529$ & 1.000 & 0.437 \\
\hline TNM stage (III vs. I-II) & $4.051-5.924$ & $2.337-10.828$ & 0.876 & 0.386 \\
\hline T stage $\left(T_{2-4} v s . T_{1}\right)$ & $1.256-1.568$ & $1.046-2.097$ & 0.917 & 0.340 \\
\hline $\mathrm{N}$ stage $\left(\mathrm{N}_{+}\right.$vs. $\left.\mathrm{N}_{0}\right)$ & $0.893-1.114$ & $0.637-1.586$ & 0.755 & 0.358 \\
\hline IDC vs. DCIS & $1.280-1.477$ & $0.428-3.928$ & 1.000 & 0.817 \\
\hline IDC vs. ILC & $1.927-3.935$ & $0.890-10.835$ & 0.221 & 0.056 \\
\hline LVI (positive vs. negative) & $0.806-1.021$ & $0.656-1.505$ & 1.000 & 0.484 \\
\hline BVI (positive vs. negative) & $2.558-2.683$ & $0.936-7.689$ & 1.000 & - \\
\hline VPI (high vs. low) & $2.958-3.043$ & $1.650-5.302$ & 0.296 & 0.066 \\
\hline \multicolumn{5}{|c|}{ Nestin expression and immunohistochemical markers } \\
\hline ER (positive vs. negative) & $0.107-0.134$ & $0.064-0.208$ & 0.243 & 0.306 \\
\hline PR (positive vs. negative) & $0.167-0.218$ & $0.105-0.341$ & 0.474 & 0.455 \\
\hline HER2 (positive vs. negative) & $0.610-0.826$ & $0.321-1.268$ & 0.013 & 0.068 \\
\hline Ki-67 (high vs. low) & $4.998-7.542$ & $2.807-14.262$ & 0.462 & 0.059 \\
\hline TNBC vs. Non-TNBC & $7.898-10.775$ & $5.246-18.386$ & 0.348 & 0.657 \\
\hline CK5 (positive vs. negative) & $7.605-9.786$ & $5.983-14.333$ & 0.462 & 0.023 \\
\hline P-cadherin (positive vs. negative) & $7.440-8.244$ & $4.945-12.964$ & 0.308 & 0.123 \\
\hline EGFR (positive vs. negative) & $6.306-7.034$ & $3.962-10.244$ & 1.000 & 0.888 \\
\hline BLP1 (present vs. absent) & $19.543-23.784$ & $11.296-41.447$ & 1.000 & 0.629 \\
\hline BLP2 (present vs. absent) & 15.339-20.293 & $9.432-33.109$ & 0.308 & 0.280 \\
\hline BLP3 (present vs. absent) & $12.265-13.134$ & $4.821-31.205$ & 0.296 & 0.253 \\
\hline BLP4 (present vs. absent) & $19.715-23.878$ & $9.672-48.403$ & 0.296 & 0.468 \\
\hline BLP5 (present vs. absent) & $22.230-26.590$ & $11.294-53.144$ & 1.000 & 0.683 \\
\hline p53 (positive vs. negative) & $3.906-5.397$ & $2.619-8.421$ & 0.221 & 0.055 \\
\hline FOXA1 (positive vs. negative) & $0.043-0.241$ & $0.009-0.593$ & 1.000 & - \\
\hline
\end{tabular}

of the association between the expression of nestin and CK5 (Egger's test, $\mathrm{P}=0.023$ ), and the meta-analysis incorporating these three imputed studies demonstrated the semblable result (adjusted OR $=7.091$, 95\% CI [5.777-8.704], P < 0.001) (Fig. 8b). Despite a significant publication bias in the analysis of the association between nestin expression and HER2 status (Begg's test, $\mathrm{P}=0.013$ ), trim and fill analysis revealed that no trimming was performed and thus pooled data remained unchanged. In conclusion, the results of the three pooled studies were robust in spite of significant publication bias.

\section{Discussion}

Nestin, initially identified as a neural stem cell marker, has recently been implicated as a positive regulator of proliferation, survival, and invasiveness of breast CSCs via the $\mathrm{Wnt} / \beta$-catenin pathway $[20,58]$. Upregulated expression of nestin promoted the tumorigenicity of breast CSCs, whereas inhibition of nestin expression can significantly induce CSC cycle arrest at G2/M phases and promote CSC apoptosis [20]. Silencing nestin expression can notably suppress the epithelial-mesenchymal transition (EMT) process that is closely related to the invasiveness of breast CSCs $[20,26,59,60]$. Therefore, it is 

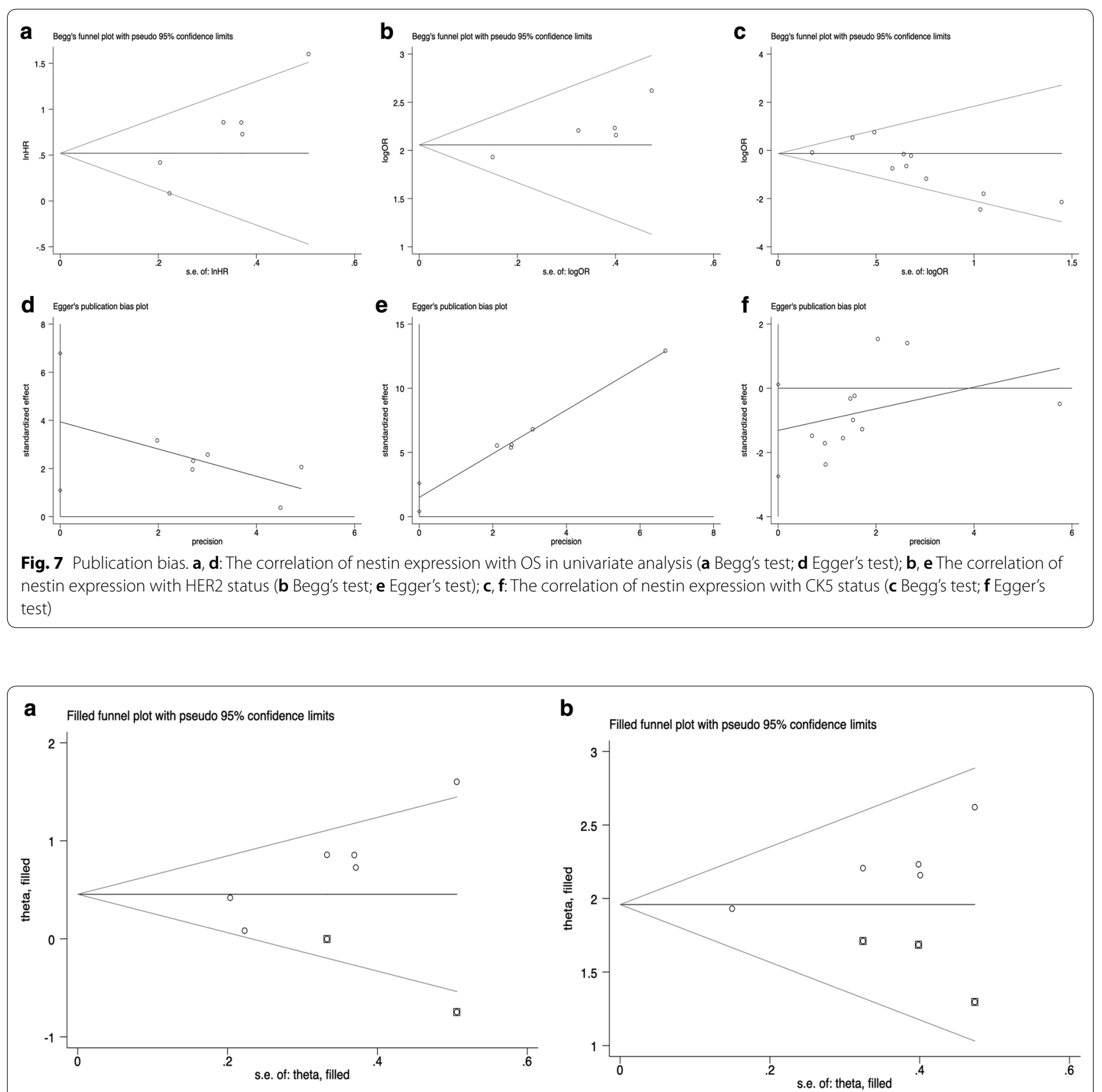

Fig. 8 Trim and fill analysis. a The correlation of nestin expression with OS in univariate analysis; $\mathbf{b}$ The correlation of nestin expression with CK5 status

imperative to elucidate the clinical implication of nestin in breast cancer patients.

Previous studies investigated the potential prognostic and clinicopathological association of nestin expression with breast cancer patients. However, the eligible studies included in this meta-analysis were diversified and their results were contradictory. We first conducted the present meta-analysis to systematically analyze the prognostic impact of nestin expression on breast cancer patients. Pooled results demonstrated that positive expression of nestin predicted shorter BCSS and reduced OS of breast cancer patients in both univariate and multivariate analyses. Therefore, nestin is an independent factor for worse BCSS and OS of breast cancer patients. Besides, nestin-positive expression was also associated with RFS in univariate analysis, but not with DMFS based 
on univariate data. Of note, because only limited studies were available for the pooled analyses of the prognostic impact of nestin expression on DMFS and RFS, it was highly possible to draw unreliable and biased conclusions. Therefore, more studies to investigate the relationship between nestin expression and survival outcomes of breast cancer patients are warranted.

We then evaluated the correlation between nestin expression and clinicopathological characteristics of breast cancer patients in this meta-analysis. Nestin positivity was closely associated with earlier age for the onset of disease, higher histological grade, larger tumor size, and IDC, but not with lymph node metastasis. Nestin expression was correlated with ER negativity, PR negativity, high Ki-67 index, and positive p53 nuclear expression, but not with HER-2 status. In addition, positive expression of nestin was strongly correlated with three basal markers (CK5, P-cadherin, and EGFR) and five basal-like profiles (BLP1-BLP5). More importantly, nestin was predominantly expressed in malignant breast cancer, especially in TNBC and basal-like phenotype. Nestin expression was also revealed to be predominant in patients treated with chemotherapy and be downregulated in patients receiving hormonal therapy. These results are in accordance with the negative correlation of nestin expression with hormonal receptor expression. In view of results mentioned above, nestin expression was correlated with unfavorable clinicopathological features in breast cancer patients. Enhanced expression of nestin is a promising indicator for the malignancy of breast cancer. Of note, although Li et al. [32] evaluated nestin as a selective marker of basal epithelial breast tumors, it was reported that high levels of nestin expression were also detected in non-TNBCs and non-core basal subtypes, such as in a small group of luminal subtypes according to some studies [21-23, 25-28, 55, 56]. As a result, nestin is not actually an optimized predictor of TNBC or basallike phenotype.

Tumor angiogenesis on the basis of new vascular network formation plays a vital role in the progression and invasiveness of breast cancer [61, 62]. Apart from participation in the angiogenesis of wound healing and tissue repair in various normal tissues, nestin expression has also been implicated in tumor angiogenesis [31, 63]. Nestin-positive breast cancer stem/progenitor cells can differentiate into endothelial cells which would participate in tumor growth and vascularization [64]. Accumulated evidence suggested that nestin expression in the blood vessels is basically localized to the newly formed endothelial cell of tumor vessels $[65,66]$. In this meta-analysis, we validated that nestin expression was significantly associated with positive blood vessel invasion and high vascular proliferation index in $\mathrm{BC}$, but not with lymph vessel invasion. Besides, according to the study by Nowak et al. [50], increased nestin-positive microvessel density (Nestin ${ }^{+} \mathrm{MVD}$ ) was found to be significantly associated with a shorter OS, earlier relapse, higher histological grade, and TNBCs. In consequence, nestin can be a potential angiogenesis-specific marker in $\mathrm{BC}$.

Several studies also assessed the potential diagnostic and prognostic value of co-expression of nestin and some other biomarkers in breast cancer. Asleh et al. [52, 67] revealed that IHC detection of nestin and inositol polyphosphate-4-phosphatase (INPP4b) as an optimized panel of markers can be a more specific indicator for the basal-like subtype of BC regardless of ER status. Nestin positivity or loss of INPP4b $\left(\mathrm{Nestin}^{+}\right.$or INPP4b $\left.{ }^{-}\right)$ is an independent prognostic for BCSS of basal-like cases with weak ER positivity [67]. Liu et al. [25] found that co-expression of nestin and octamer-binding transcription factor 4 (Oct-4) was an independent prognostic factor for breast cancer $(\mathrm{OR}=10.114,95 \%$ CI [1.632, 62.699], $\mathrm{P}=0.013)$. Nestin/Oct-4 co-expression was significantly correlated with poor prognosis, younger age, lymph node metastasis, and TNBCs [25]. Besides, a study by Rögelsperger et al. [68] demonstrated that abundant expression of G-protein-coupled receptor for melatonin (MT1) was frequently observed in advanced breast cancer specimens. Previous studies showed that MT1 activation by melatonin can induce anti-tumor effects and inhibit the cell growth and metastasis of breast cancer $[69,70]$. However, a high level of MT1 expression was also detected in breast cancer cells and was involved in tumor initiation and progression of breast cancer on basis of its activation independent of melatonin [71, 72]. Co-localization of nestin and MT1 in invasive breast cancer was associated with worse prognosis and advanced histological stage [68]. As a consequence, IHC detection of co-expression of nestin and relevant biomarkers provides a novel approach to more precisely predicting the prognosis of breast cancer.

There were some potential limitations to this metaanalysis. First, partial survival data were extracted from Kaplan-Meier curves in some studies, which are less dependable than data directly obtained from articles. Second, the criterion of positive nestin expression was verified among eligible studies, which may result in the heterogeneity of studies. Finally, only limited studies were included into the multivariate analysis of the correlation between nestin expression and survival outcomes, which may draw biased conclusions. This warrants further studies added into the meta-analysis of the prognostic impact of nestin expression on survival outcomes to obtain robust and reliable results. Despite the limitations mentioned above, the present meta-analysis still revealed 
the prognostic value of nestin expression in breast cancer patients.

\section{Conclusions}

In summary, this meta-analysis revealed the prognostic value and clinicopathological significance of nestin expression in breast cancer. Nestin is an independent prognostic factor for worse BCSS and OS of breast cancer patients. Besides, nestin is also a valuable biomarker for unfavorable clinicopathological features and tumor angiogenesis of breast cancer. More prospective studies with multivariate analysis to evaluate nestin as a therapeutic target for malignant breast cancer, especially for TNBC and basal-like phenotype, are warranted.

\section{Supplementary information}

Supplementary information accompanies this paper at https://doi. org/10.1186/s12935-020-01252-5.

\begin{abstract}
Additional file 1: Table S1. Newcastle-Ottawa Scale for assessing the quality of studies in quantitative analysis.

Additional file 2: Fig. S1. Sensitivity analysis. (1) BCSS (univariate analysis); (2) BCSS (multivariate analysis); (3) OS (univariate analysis); (4) OS (multivariate analysis); (5) DMFS (univariate analysis); (6) RFS (univariate analysis); (7) TNM stage (grade III vs. grade I-II); (8) Tumor size ( $T_{2-4}$ Vs. $\left.T_{1}\right)$; (9) Lymph node metastasis ( $N_{+}$vs. $\left.N_{0}\right)$; (10) IDC vs. DCIS; (11) BVI (positive vs. negative); (12) VPI (high vs. low); (13) ER (positive vs. negative); (14) PR (positive vs. negative); (15) HER2 (positive vs. negative); (16) Ki-67 (high vs. low); (17) TNBC vs. Non-TNBC; (18) CK5 (positive vs. negative); (19) P-cadherin (positive vs. negative); (20) EGFR (positive vs. negative); (21) BLP1 (present vs. absent); (22) BLP2 (present vs. absent); (23) BLP3 (present vs. absent); (24) BLP4 (present vs. absent); (25) BLP5 (present vs. absent); (26) p53 (positive vs. negative); (27) FOXA1 (positive vs. negative).
\end{abstract}

Additional file 3: Fig. S2. Begg's test. (1) BCSS (univariate analysis); (2) BCSS (multivariate analysis); (3) OS (multivariate analysis); (4) DMFS (univariate analysis); (5) RFS (univariate analysis); (6) Age (age > 35 vs. age <35); (7) TNM stage (grade III vs. grade I-II); (8) Tumor size ( $T_{2-4}$ Vs. $\left.T_{1}\right)$; (9) Lymph node metastasis $\left(N_{+}\right.$Vs. $\left.N_{0}\right)$; (10) IDC vs. DCIS; (11) IDC Vs. ILC; (12) LVI (positive vs. negative); (13) BVI (positive vs. negative); (14) VPI (high vs. low); (15) ER (positive vs. negative); (16) PR (positive vs. negative); (17) Ki-67 (high vs. low); (18) TNBC vs. Non-TNBC; (19) P-cadherin (positive vs. negative); (20) EGFR (positive vs. negative); (21) BLP1 (present vs. absent); (22) BLP2 (present vs. absent); (23) BLP3 (present vs. absent); (24) BLP4 (present vs. absent); (25) BLP5 (present vs. absent); (26) p53 (positive vs. negative); (27) FOXA1 (positive vs. negative).

Additional file 4: Fig. S3. Egger's test. (1) BCSS (univariate analysis); (2) OS (multivariate analysis); (3) Age (age > 35 vs. age < 35); (4) TNM stage (grade III vs. grade I-II); (5) Tumor size ( $\mathrm{T}_{2-4}$ vs. $\left.\mathrm{T}_{1}\right)$; $(6)$ Lymph node metastasis $\left(\mathrm{N}_{+}\right.$ vs. $N_{0}$ ); (7) IDC vs. DCIS; (8) IDC vs. ILC; (9) LVI (positive vs. negative); (10) VPI (high vs. low); (11) ER (positive vs. negative); (12) PR (positive vs. negative); (13) Ki-67 (high vs. low); (14) TNBC vs. Non-TNBC; (15) P-cadherin (positive vs. negative); (16) EGFR (positive vs. negative); (17) BLP1 (present vs. absent); (18) BLP2 (present vs. absent); (19) BLP3 (present vs. absent); (20) BLP4 (present vs. absent); (21) BLP5 (present vs. absent); (22) p53 (positive vs. negative).

\section{Abbreviations}

BC: Breast cancer; BCSS: Breast cancer-specific survival; BLP: Basal-like profiles; BVI: Blood vessel invasion; CBP: Core basal phenotype; Cl: Confidence interval; CK5: Cytokeratin 5; CSC: Cancer stem cell; DCIS: Ductal carcinoma in situ; DMFS: Distant metastasis-free survival; EGFR: Epidermal growth factor receptor; EMT: Epithelial-mesenchymal transition; ER: Estrogen receptor; FOXA1:
Forkhead box protein A1; HER2: Human epidermal growth factor receptor 2; HR: Hazard ratio; IBC: Invasive breast cancer; IDC: Invasive ductal carcinoma; IF: Intermediate filament; IHC: Immunohistochemistry; INPP4b: Inositol polyphosphate-4-phosphatase; LVI: Lymph vessel invasion; M: Multivariate analysis; MBC: Metastatic breast cancer; MT1: G-protein-coupled receptor for melatonin; MVD: Microvessel density; Oct-4: Octamer-binding transcription factor 4; OR: Odds ratio; OS: Overall survival; PFS: Progression-free survival; PR: Progesterone receptor; qPRT-PCR: Quantitative real time polymerase chain reaction; RCT: Randomized controlled trial; RFS: Recurrence-free survival; TNBC: Triple-negative breast cancer; TNM: Tumor node metastasis; U: Univariate analysis; VPI: Vascular proliferation index.

\section{Acknowledgements}

We sincerely thank Dr. Cindy Bi for her linguistic assistance during the preparation of this manuscript.

\section{Authors' contributions}

$X Y Z$, WTG and KX contributed conception and design of the study, analysis and interpretation of data; XYZ, CSX, WTG, LC, KG, AZY and KX drafted the manuscript; $K X$ contributed to study supervision. All authors contributed to manuscript revision. All authors read and approved the final manuscript.

\section{Funding \\ None.}

\section{Availability of data and materials}

The datasets used in this study are available from the corresponding author upon reasonable request.

\section{Ethics approval and consent to participate}

Not applicable.

\section{Consent for publication \\ Not applicable.}

\section{Competing interests}

The authors declare that they have no competing interests.

\section{Author details}

${ }^{1}$ Department of Cardiovascular Medicine, The Second Affiliated Hospital, Zhejiang University School of Medicine, Hangzhou 310003, China. ${ }^{2}$ Department of Cardiovascular Medicine, Xiangya Hospital, Central South University, Changsha 410008, China. ${ }^{3}$ The Third Xiangya Hospital, Central South University, Changsha 410013, China. ${ }^{4}$ Center for Inflammation and Epigenetics, Houston Methodist Research Institute, Houston, TX 77030, USA. ${ }^{5}$ Department of Radiology, The Affiliated Huai'an No.1 People's Hospital of Nanjing Medical University, Huai'an 223300, China. ${ }^{6}$ Department of Radiology, Zhongda Hospital, Medical School of Southeast University, Nanjing 210009, China. ${ }^{7}$ Department of General Surgery, The Third Xiangya Hospital, Central South University, Changsha 410013, China. ${ }^{8}$ Department of Otolaryngology Head and Neck Surgery, Xiangya Hospital, Central South University, Changsha 410008, China. ${ }^{9}$ Department of Urology, Xiangya Hospital, Central South University, Changsha 410008, China. ${ }^{10}$ Department of General Surgery, The First Affiliated Hospital, Zhejiang University School of Medicine, Hangzhou 310003, China. ${ }^{11}$ Department of Neurosurgery, Xiangya Hospital, Central South University, Changsha 410008, China.

Received: 26 January 2020 Accepted: 10 May 2020

Published online: 14 May 2020

\section{References}

1. DeSantis CE, Ma J, Gaudet MM, Newman LA, Miller KD, Goding Sauer A, Jemal A, Siegel RL. Breast cancer statistics, 2019. CA Cancer J Clin. 2019;69(6):438-51.

2. Zardavas D, Irrthum A, Swanton C, Piccart M. Clinical management of breast cancer heterogeneity. Nat Rev Clin Oncol. 2015;12(7):381-94.

3. Fu NY, Nolan E, Lindeman GJ, Visvader JE. Stem cells and the differentiation hierarchy in mammary gland development. Physiol Rev. 2020;100(2):489-523. 
4. Fang $Y$, Zhang $Q$, Wang $X$, Yang $X$, Wang $X$, Huang Z, Jiao $Y$, Wang J. Quantitative phosphoproteomics reveals genistein as a modulator of cell cycle and DNA damage response pathways in triple-negative breast cancer cells. Int J Oncol. 2016;48(3):1016-28.

5. van Reesema LLS, Zheleva V, Winston JS, Jansen RJ, O'Connor CF, Isbell AJ, Bian M, Qin R, Bassett PT, Hinson VJ, et al. SIAH and EGFR, two RAS pathway biomarkers, are highly prognostic in locally advanced and metastatic breast cancer. EBioMedicine. 2016;11:183-98.

6. Gnant M, Harbeck N, Thomssen C. St. Gallen 2011: summary of the consensus discussion. Breast Care. 2011;6(2):136-41.

7. Perou CM, Sorlie T, Eisen MB, van de Rijn M, Jeffrey SS, Rees CA, Pollack JR, Ross DT, Johnsen H, Akslen LA, et al. Molecular portraits of human breast tumours. Nature. 2000:406(6797):747-52.

8. van't Veer LJ, Dai H, van de Vijver MJ, He YD, Hart AA, Mao M, Peterse HL, van der Kooy K, Marton MJ, Witteveen AT, et al. Gene expression profiling predicts clinical outcome of breast cancer. Nature. 2002;415(6871):530-6.

9. Sorlie T, Perou CM, Tibshirani R, Aas T, Geisler S, Johnsen H, Hastie T, Eisen $M B$, van de Rijn M, Jeffrey SS, et al. Gene expression patterns of breast carcinomas distinguish tumor subclasses with clinical implications. Proc Natl Acad Sci USA. 2001;98(19):10869-74.

10. Sorlie T, Tibshirani R, Parker J, Hastie T, Marron JS, Nobel A, Deng S, Johnsen $\mathrm{H}$, Pesich R, Geisler S, et al. Repeated observation of breast tumor subtypes in independent gene expression data sets. Proc Natl Acad Sci USA. 2003;100(14):8418-23.

11. Matsen $C B$, Neumayer $L A$. Breast cancer: a review for the general surgeon. JAMA Surg. 2013;148(10):971-9.

12. Coates AS, Winer EP, Goldhirsch A, Gelber RD, Gnant M, Piccart-Gebhart M, Thurlimann B, Senn HJ, Panel M. Tailoring therapies-improving the management of early breast cancer: St Gallen International Expert Consensus on the primary therapy of early breast cancer 2015. Ann Oncol. 2015;26(8):1533-46.

13. Aebi S, Gelber S, Anderson SJ, Lang I, Robidoux A, Martin M, Nortier JW, Paterson AH, Rimawi MF, Canada JM, et al. Chemotherapy for isolated locoregional recurrence of breast cancer (CALOR): a randomised trial. Lancet Oncol. 2014;15(2):156-63.

14. Haviland JS, Owen JR, Dewar JA, Agrawal RK, Barrett J, Barrett-Lee PJ, Dobbs HJ, Hopwood P, Lawton PA, Magee BJ, et al. The UK Standardisation of Breast Radiotherapy (START) trials of radiotherapy hypofractionation for treatment of early breast cancer: 10-year follow-up results of two randomised controlled trials. Lancet Oncol. 2013;14(11):1086-94.

15. Fan W, Chang J, Fu P. Endocrine therapy resistance in breast cancer: current status, possible mechanisms and overcoming strategies. Fut Med Chem. 2015;7(12):1511-9.

16. Smith A, Farrah K. In: Gene expression profiling tests for breast cancer: a rapid qualitative review. Ottawa (ON); 2019.

17. Jia Y, Chen $Y$, Wang $Q$, Jayasinghe U, Luo X, Wei Q, Wang J, Xiong H, Chen $\mathrm{C}, \mathrm{Xu} \mathrm{B}$, et al. Exosome: emerging biomarker in breast cancer. Oncotarget. 2017:8(25):41717-33.

18. Jafari SH, Saadatpour Z, Salmaninejad A, Momeni F, Mokhtari M, Nahand JS, Rahmati M, Mirzaei H, Kianmehr M. Breast cancer diagnosis: imaging techniques and biochemical markers. J Cell Physiol. 2018;233(7):5200-13.

19. Duffy MJ, Walsh S, McDermott EW, Crown J. Biomarkers in breast cancer: where are we and where are we going? Adv Clin Chem. 2015;71:1-23.

20. Zhao ZW, Lu P, Zhang H, Xu HM, Gao NN, Li M, Liu CG. Nestin positively regulates the $\mathrm{Wnt} /$ beta-catenin pathway and the proliferation, survival and invasiveness of breast cancer stem cells. Breast Cancer Res. 2014;16(4):408.

21. Asleh K, Won JR, Gao DX, Voduc KD, Nielsen TO. Nestin expression in breast cancer: association with prognosis and subtype on 3641 cases with long-term follow-up. Breast Cancer Res Treat. 2018;168(1):107-15.

22. De Lara S, Nyqvist J, Werner Rönnerman E, Helou K, Kenne Sarenmalm E, Einbeigi Z, Karlsson P, Parris TZ, Kovács A. The prognostic relevance of FOXA1 and Nestin expression in breast cancer metastases: a retrospective study of 164 cases during a 10-year period (2004-2014). BMC Cancer. 2019;19(1):187.

23. Gao NN, Xu H, Liu CG, Xu HM, Chen GL, Wang XM, Li YY, Wang Y. Nestin: predicting specific survival factors for breast cancer. Tumor Biol. 2014;35(3):1751-5.

24. Kruger K, Wik E, Knutsvik G, Nalwoga H, Klingen TA, Arnes JB, Chen Y, Mannelqvist M, Dimitrakopoulou K, Stefansson IM, et al. Expression of Nestin associates with BRCA1 mutations, a basal-like phenotype and aggressive breast cancer. Sci Rep. 2017;7(1):1089.

25. Liu C, Cao X, Zhang Y, Xu H, Zhang R, Wu Y, Lu P, Jin F. Co-expression of Oct- 4 and Nestin in human breast cancers. Mol Biol Rep. 2012:39(5):5875-81.

26. Liu CG, Chen B, Zhu J, Zhang RS, Yao F, Jin F, Xu HM, Lu P. Clinical implications for nestin protein expression in breast cancer. Cancer Sci. 2010;101(3):815-9.

27. Parry S, Savage K, Marchiò C, Reis-Filho JS. Nestin is expressed in basal-like and triple negative breast cancers. J Clin Pathol. 2008;61 (9):1045-50.

28. Piras F, lonta MT, Lai S, Perra MT, Atzori F, Minerba L, Pusceddu V, Maxia C, Murtas D, Demurtas P, et al. Nestin expression associates with poor prognosis and triple negative phenotype in locally advanced (T4) breast cancer. Eur J Histochem. 2011;55(4):e39.

29. Guerette D, Khan PA, Savard PE, Vincent M. Molecular evolution of type VI intermediate filament proteins. BMC Evol Biol. 2007;7:164.

30. Bernal A, Arranz L. Nestin-expressing progenitor cells: function, identity and therapeutic implications. Cell Mol Life Sci. 2018:75(12):2177-95.

31. Cheng F, Eriksson JE. Intermediate filaments and the regulation of cell motility during regeneration and wound healing. Cold Spring Harb Perspect Biol. 2017;9(9):a022046.

32. Li H, Cherukuri P, Li N, Cowling V, Spinella M, Cole M, Godwin AK, Wells W, DiRenzo J. Nestin is expressed in the basal/myoepithelial layer of the mammary gland and is a selective marker of basal epithelial breast tumors. Cancer Res. 2007;67(2):501-10.

33. Neradil J, Veselska R. Nestin as a marker of cancer stem cells. Cancer Sci. 2015;106(7):803-11.

34. Costa CD, Justo AA, Kobayashi PE, Story MM, Palmieri C, Laufer Amorim R, Fonseca-Alves CE. Characterization of OCT3/4, Nestin, NANOG, CD44 and CD24 as stem cell markers in canine prostate cancer. Int J Biochem Cell Biol. 2019:108:21-8.

35. Jin X, Jin X, Jung JE, Beck S, Kim H. Cell surface Nestin is a biomarker for glioma stem cells. Biochem Biophys Res Commun. 2013;433(4):496-501.

36. Kleeberger W, Bova GS, Nielsen ME, Herawi M, Chuang AY, Epstein Jl, Berman DM. Roles for the stem cell associated intermediate filament Nestin in prostate cancer migration and metastasis. Cancer Res. 2007;67(19):9199-206.

37. Beck B, Blanpain C. Unravelling cancer stem cell potential. Nat Rev Cancer. 2013;13(10):727-38.

38. Vlashi E, Pajonk F. Cancer stem cells, cancer cell plasticity and radiation therapy. Semin Cancer Biol. 2015;31:28-35.

39. Batlle $\mathrm{E}$, Clevers $\mathrm{H}$. Cancer stem cells revisited. Nat Med. 2017;23(10):1124-34

40. Ladstein RG, Bachmann IM, Straume O, Akslen LA. Nestin expression is associated with aggressive cutaneous melanoma of the nodular type. Mod Pathol. 2014;27(3):396-401.

41. Tsujimura T, Makiishi-Shimobayashi C, Lundkvist J, Lendahl U, Nakasho K, Sugihara A, Iwasaki T, Mano M, Yamada N, Yamashita K, et al. Expression of the intermediate filament nestin in gastrointestinal stromal tumors and interstitial cells of Cajal. Am J Pathol. 2001;158(3):817-23.

42. Wang J, Cai J, Huang Y, Ke Q, Wu B, Wang S, Han X, Wang T, Wang Y, Li $W$, et al. Nestin regulates proliferation and invasion of gastrointestinal stromal tumor cells by altering mitochondrial dynamics. Oncogene. 2016;35(24):3139-50.

43. Yamahatsu K, Matsuda Y, Ishiwata T, Uchida E, Naito Z. Nestin as a novel therapeutic target for pancreatic cancer via tumor angiogenesis. Int J Oncol. 2012;40(5):1345-57.

44. Cros J, Sbidian E, Posseme K, Letierce A, Guettier C, Benoit G, Ferlicot S. Nestin expression on tumour vessels and tumour-infiltrating macrophages define a poor prognosis subgroup of pt 1 clear cell renal cell carcinoma. Virchows Arch. 2016;469(3):331-7.

45. Takakuwa O, Maeno K, Kunii E, Ozasa H, Hijikata H, Uemura T, Kasai D, Ohkubo H, Miyazaki M, Oguri T, et al. Involvement of intermediate filament nestin in cell growth of small-cell lung cancer. Lung Cancer. 2013;81(2):174-9.

46. Zhao L, Li J, Liu M, Zhou H, Zou H, Wei Y, Sun K, Li G, Li S, Pang L. The clinicopathological parameters significance of CD133 and Nestin in epithelial ovarian cancer: a meta-analysis. Future Oncol. 2017;13(28):2555-70.

47. Li S, Lai Y, Fan J, Shen C, Che G. Clinicopathological and prognostic significance of Nestin expression in patients with non-small cell lung cancer: a systematic review and meta-analysis. Clin Exp Med. 2017;17(2):161-74. 
48. Lv D, Lu L, Hu Z, Fei Z, Liu M, Wei L, Xu J. Nestin expression is associated with poor clinicopathological features and prognosis in glioma patients: an association study and meta-analysis. Mol Neurobiol. 2017:54(1):727-35.

49. Wu B, Sun C, Feng F, Ge M, Xia L. Do relevant markers of cancer stem cells CD133 and Nestin indicate a poor prognosis in glioma patients? A systematic review and meta-analysis. J Exp Clin Cancer Res. 2015;34:44.

50. Nowak A, Grzegrzolka J, Paprocka M, Piotrowska A, Rys J, Matkowski R, Dziegiel P. Nestin-positive microvessel density is an independent prognostic factor in breast cancer. Int J Oncol. 2017;51(2):668-76.

51. Nowak A, Grzegrzółka J, Kmiecik A, Piotrowska A, Matkowski R, Dzięgiel P. Role of nestin expression in angiogenesis and breast cancer progression. Int J Oncol. 2018;52(2):527-35.

52. Asleh K, Lyck Carstensen S, Tykjaer Jorgensen CL, Burugu S, Gao D, Won $J R$, Jensen MB, Balslev E, Laenkholm AV, Nielsen DL, et al. Basal biomarkers nestin and INPP4B predict gemcitabine benefit in metastatic breast cancer: samples from the phase III SBG0102 clinical trial. Int J Cancer. 2019;144(10):2578-86.

53. Moher D, Liberati A, Tetzlaff J, Altman DG, Group P. Preferred reporting items for systematic reviews and meta-analyses: the PRISMA statement. PLoS Med. 2009;6(7):e1000097.

54. Meisen WH, Dubin S, Sizemore ST, Mathsyaraja H, Thies K, Lehman NL, Boyer P, Jaime-Ramirez AC, Elder JB, Powell K, et al. Changes in BAl1 and nestin expression are prognostic indicators for survival and metastases in breast cancer and provide opportunities for dual targeted therapies. Mol Cancer Ther. 2015;14(1):307-14.

55. Tampaki EC, Tampakis A, Nonni A, Kontzoglou K, Patsouris E, Kouraklis G. Nestin and cluster of differentiation 146 expression in breast cancer: predicting early recurrence by targeting metastasis? Tumour Biol. 2017;39(3):1010428317691181.

56. Zhu J, Liu CG, Zhang RS, Lu Y, Jin F, Xu HM, Lu P. Relationship between nestin expression and other clinicopathological factors in breast cancer. J Chin Clin Med. 2009:4(11):622-5.

57. Marmor S, Hui JYC, Huang JL, Kizy S, Beckwith H, Blaes AH, Rueth NM, Tuttle TM. Relative effectiveness of adjuvant chemotherapy for invasive lobular compared with invasive ductal carcinoma of the breast. Cancer. 2017;123(16):3015-21.

58. Suzuki S, Namiki J, Shibata S, Mastuzaki Y, Okano H. The neural stem/ progenitor cell marker nestin is expressed in proliferative endothelial cells, but not in mature vasculature. J Histochem Cytochem. 2010;58(8):721-30.

59. Kruger K, Stefansson IM, Collett K, Arnes JB, Aas T, Akslen LA. Microvessel proliferation by co-expression of endothelial nestin and $\mathrm{Ki}-67$ is associated with a basal-like phenotype and aggressive features in breast cancer. Breast. 2013;22(3):282-8.

60. Ye X, Brabletz T, Kang Y, Longmore GD, Nieto MA, Stanger BZ, Yang J, Weinberg RA. Upholding a role for EMT in breast cancer metastasis. Nature. 2017;547(7661):E1-3.
61. Onisim A, Achimas-Cadariu A, Vlad C, Kubelac P, Achimas-Cadariu P. Current insights into the association of Nestin with tumor angiogenesis. J BUON. 2015;20(3):699-706.

62. Wang Y, Li C, Li Y, Zhu Z. Involvement of breast cancer stem cells in tumor angiogenesis. Oncol Lett. 2017;14(6):8150-5.

63. Nowak A, Dziegiel P. Implications of nestin in breast cancer pathogenesis (Review). Int J Oncol. 2018;53(2):477-87.

64. Bussolati B, Grange C, Sapino A, Camussi G. Endothelial cell differentiation of human breast tumour stem/progenitor cells. J Cell Mol Med. 2009;13(2):309-19.

65. Mokry J, Cizkova D, Filip S, Ehrmann J, Osterreicher J, Kolar Z, English D. Nestin expression by newly formed human blood vessels. Stem Cells Dev. 2004;13(6):658-64.

66. Liang ZW, Wang Z, Chen H, Li C, Zhou T, Yang Z, Yang X, Yang Y, Gao G, Cai W. Nestin-mediated cytoskeletal remodeling in endothelial cells: novel mechanistic insight into VEGF-induced cell migration in angiogenesis. Am J Physiol Cell Physiol. 2015;308(5):C349-58.

67. Asleh-Aburaya K, Sheffield BS, Kos Z, Won JR, Wang XQ, Gao D, Wolber R, Gilks CB, Bernard PS, Chia SK, et al. Basal biomarkers nestin and INPP4b identify intrinsic subtypes accurately in breast cancers that are weakly positive for oestrogen receptor. Histopathology. 2017;70(2):185-94.

68. Rogelsperger $\mathrm{O}$, Ekmekcioglu C, Jager W, Klimpfinger M, Konigsberg $R$, Krenbek D, Sellner F, Thalhammer T. Coexpression of the melatonin receptor 1 and nestin in human breast cancer specimens. J Pineal Res. 2009;46(4):422-32.

69. Yuan L, Collins AR, Dai J, Dubocovich ML, Hill SM. MT(1) melatonin receptor overexpression enhances the growth suppressive effect of melatonin in human breast cancer cells. Mol Cell Endocrinol. 2002;192(1-2):147-56.

70. Kiefer T, Ram PT, Yuan L, Hill SM. Melatonin inhibits estrogen receptor transactivation and cAMP levels in breast cancer cells. Breast Cancer Res Treat. 2002;71(1):37-45.

71. Dillon DC, Easley SE, Asch BB, Cheney RT, Brydon L, Jockers R, Winston JS, Brooks JS, Hurd T, Asch HL. Differential expression of high-affinity melatonin receptors (MT1) in normal and malignant human breast tissue. Am J Clin Pathol. 2002;118(3):451-8.

72. Jockers R, Maurice P, Boutin JA, Delagrange P. Melatonin receptors, heterodimerization, signal transduction and binding sites: what's new? $\mathrm{Br}$ J Pharmacol. 2008;154(6):1182-95.

\section{Publisher's Note}

Springer Nature remains neutral with regard to jurisdictional claims in published maps and institutional affiliations.
Ready to submit your research? Choose BMC and benefit from:

- fast, convenient online submission

- thorough peer review by experienced researchers in your field

- rapid publication on acceptance

- support for research data, including large and complex data types

- gold Open Access which fosters wider collaboration and increased citations

- maximum visibility for your research: over 100M website views per year

At BMC, research is always in progress.

Learn more biomedcentral.com/submissions 